\title{
ANALISIS CUSTOMER RELATIONSHIP MANAGEMENT TERHADAP KEPUASAN PASIEN PUSAT JANTUNG NASIONAL HARAPAN KITA
}

\author{
S. Liawatimena ${ }^{1}$; Teguh Arifianto ${ }^{2}$; Yunina Saliu ${ }^{3}$; Hartono Agus Salim ${ }^{4}$
}

\begin{abstract}
The research tries to find out how big the influence of Customer Relationship Management of Heart Centre Patient Harapan Kita concerning the patient satisfaction. The Customer Relationship Management divide into three main functions which is Acquisition, Enhance, and Retain. The conclusion is, if there is increased in Customer Relationship Management of Heart Centre Patient Harapan Kita, it will increased the patient satisfaction also.
\end{abstract}

Keywords: customer relationship management, patient

ABSTRAK
Penelitian bertujuan untuk mengetahui seberapa besar pengaruh Customer Relationship
Management PJN Harapan Kita terhadap kepuasan pasien. Customer Relationship Management
dalam hal ini terbagi menjadi tiga fungsi utama, yaitu Acquisition, Enhance, dan Retain. Simpulan
penelitian, yaitu apabila terjadi peningkatan pada Customer Relationship Management PJN
Harapan Kita, juga dapat meningkatkan kepuasan pasien.
Kata kunci: customer relationship management, pasien

\footnotetext{
${ }^{1}$ Staf Pengajar Fakultas Ilmu Komputer, UBiNus, Jakarta

2,3,4 Sarjana Ekonomi, Jurusan Manajemen, Fakultas Ekonomi, UBiNus, Jakarta
} 


\section{PENDAHULUAN}

Beberapa tahun terakhir ini perkembangan dunia bisnis sangatlah cepat dan membuat pihak yang terlibat di dalamnya harus bekerja keras agar keberadaan mereka tetap diakui oleh pasar. Para pelaku bisnis harus mulai berpikir bagaimana cara mengalahkan para pesaing dan senantiasa meningkatkan kompetensi untuk dapat menghadapi perkembangan yang akan datang dalam mencapai pangsa pasar yang luas dan target yang diinginkan. Salah satu cara yang dapat dilakukan oleh manajemen perusahaan adalah dengan berusaha mengakuisisi, meningkatkan, dan mempertahankan pelanggan. Di lain pihak, pelanggan menghendaki biaya yang dikeluarkan murah dan kecepatan dalam pelayanan, keamanan, kejelasan, dan lain-lain.

Bila berbicara mengenai tuntutan pelanggan, sampailah pada strategi perusahaan terhadap pelanggannya. Bagian operasional yang baik memang dapat menekan biaya yang dikeluarkan sehingga pelanggan dapat memperoleh harga yang serendah-rendahnya. Akan tetapi, itu saja dirasa kurang cukup bagi pelanggan sebab mereka menginginkan yang lebih dari dimensi pelayanan seperti kecepatan, kenyamanan, dan personalisasi. Kesemuanya itu harus terintegrasi sehingga dapat dilakukan secara efisien dan fleksibel bagi kedua belah pihak. Hal itu menyebabkan Customer Relationship Management menyumbang peranan yang cukup besar dalam kesuksesan suatu lembaga atau perusahaan.

Di Indonesia, saat ini sistem pelayanan dalam berbagai bidang masih sangat kurang karena seringkali para pelanggan merasa kecewa atas jawaban dari pertanyaan yang mereka lontarkan kepada pihak perusahaan, bahkan tidak sedikit yang tidak mau menjawab pertanyaan tersebut apalagi yang bersifat online. Oleh karena itulah sistem Customer Relationship Management harus diperhatikan agar pelanggan merasa puas dan setia pada produk atau jasa yang ditawarkan perusahaan. Dalam penelitian yang dilakukan, peneliti menganalisis bagaimana Pusat Jantung Nasional Harapan Kita menangani pelangggannya (dalam hal ini pasien PJN Harapan Kita) dan terutama mengenai bagaimana Pusat Jantung Nasional Harapan Kita mengakuisisi, mempertahankan, dan meningkatkan kepuasan konsumennya. Hal itu dianalisis karena peneliti melihat bahwa Pusat Jantung Nasional Harapan Kita bertujuan menyelenggarakan pelayanan paripurna yang terjangkau oleh semua kalangan. Berdasarkan uraian di atas, dapat dilakukan identifikasi masalah sebagai berikut.

1. Bagaimana Customer Relationship Management Pusat Jantung Nasional Harapan Kita mempengaruhi kepuasan pasien PJN Harapan Kita?

2. Bagaimanakah meningkatkan Customer Relationship Management Pusat Jantung Nasional Harapan Kita agar sesuai dengan harapan pasien?

Tujuan Penelitian ini sebagai berikut.

1. Menganalisis Customer Relationship Management yang diterapkan Pusat Jantung Nasional Harapan Kita dalam memenuhi kepuasan pasiennya.

2. Mengevaluasi Customer Relationship Management Pusat Jantung Nasional Harapan Kita agar dapat menyusun strategi untuk meningkatkan CRM PJN Harapan Kita.

Manfaat Penelitian ini sebagai berikut. 
1. Membantu Pusat Jantung Nasional Harapan Kita agar dapat meningkatkan kepuasan pasien sesuai dengan harapan pasien dan mewujudkan cita-cita yang terdapat dalam Visi dan Misi Pusat Jantung Nasional Harapan Kita.

2. Untuk mengetahui kelebihan dan kelemahan Customer Relationship Management pada Pusat Jantung Nasional Harapan Kita.

3. Mengetahui faktor penting apa saja yang perlu diperhatikan dan ditingkatkan agar di kemudian hari pasien PJN Harapan Kita dapat merasa lebih diperhatikan dengan adanya peningkatan Customer Relationship Management.

\section{Fokus Pelanggan}

\section{Definisi Pelanggan}

Pelanggan adalah masyarakat yang umumnya membutuhkan produk atau jasa yang berpotensi untuk melakukan pembelian (Yoeti, 1999:11).

\section{Kepuasan Pelanggan}

Berikut ini diuraikan beberapa ungkapan mengenai kepuasan pelanggan.

1. Kepuasan pelanggan didefinisikan sebagai respons pelanggan terhadap ketidaksesuaian antara tingkat kepentingan sebelumnya dan kinerja aktual yang dirasakannya setelah pemakaian (Rangkuti, 2002:30).

2. Kepuasan pelanggan adalah pelanggan yang merasa mendapatkan value dari pemasok, produsen, atau penyedia jasa. Value dapat berasal dari produk, pelayanan, sistem atau sesuatu yang bersifat emosi. Kalau pelanggan mengatakan bahwa value adalah produk yang berkualitas, kepuasan terjadi kalau pelanggan mendapatkan produk yang berkualitas. Value bagi pelanggan adalah kenyamanan, kepuasan akan datang apabila pelayanan yang diperoleh benar-benar nyaman. Kalau value pelanggan adalah harga yang murah, pelanggan akan puas kepada produsen yang memberikan harga yang paling kompetitif (Irawan, 2002:2).

3. Menurut Kotler (1997:40) kepuasan pelanggan adalah “... a person's feeling of pleasure or disappointment resulting from comparing a product's received performance (or outcome) in relations to the person's expectation" - perasaan senang atau kecewa seseorang sebagai hasil perbandingan antara prestasi atau produk yang dirasakan dan diharapkannya. 




Gambar 1 Diagram Konsep Kepuasan Pelanggan Sumber: Rangkuti (2002:24)

\section{Pengertian dan Konsep Jasa}

Berikuti ini diuraikan pengertian jasa.

1. Berdasarkan pendapat Tjiptono (1997:23), jasa merupakan aktivitas, manfaat, atau kepuasan yang ditawarkan untuk dijual. Penawaran suatu perusahaan dapat mencakup beberapa jenis jasa.

2. Jasa merupakan pemberian suatu kinerja atau tindakan tak kasat mata dari satu pihak kepada pihak lain. Pada umumnya jasa diproduksi dan dikonsumsi secara bersamaan dan interaksi antara jasa dan penerima jasa mempengaruhi hasil jasa tersebut (Rangkuti, 2002:26).

\section{Customer Relationship Management (CRM)}

\section{Definisi Customer Relationship Management}

Berikut ini diuraikan beberapa definisi Customer Relationship Management.

1. CRM is the infrastructure that enables the delineation of and increase in customer value and the correct means by which to motivate valuable customers to remain loyal-indeed, to buy again (Dyche, 2001:4).

2. CRM is the process of acquiring, retaining, and growing profitable customers, it requires a clear focus on the service attributes that represent value to the customer and that create loyalty (Brown, 2000:8).

3. Berdasarkan pendapat Ciptamaya (1997) CRM adalah serangkaian aktivitas terintegrasi untuk mengidentifikasi, mengakuisisi, mempertahankan, dan mengembangkan pelanggan yang 
menguntungkan. Dengan tujuan utama untuk mengoptimalkan keuntungan perusahaan melalui kepuasan pelanggan.

4. Berdasarkan pendapat Kalakota (2000:111) Customer Relationship Management dapat didefinisikan sebagai integrasi dari sales, marketing, dan service strategy yang tidak menunjukkan keahlian bersandiwara (kepura-puraan) melainkan mengutamakan tindakan (sales, marketing, and service) yang terkoordinasi. Dengan demikian CRM berupaya menciptakan motto "Kami memberi bukti bukan janji" pada perusahaan yang menggunakan CRM sebagai model bisnisnya.

\section{Three Phase of Customer Relationship Management}

Berdasarkan pendapat Kalakota (2000:113), ada tiga tahap CRM.

\section{Acquiring new customers}

Mendapatkan pelanggan baru dengan mempromosikan keunggulan produk atau jasa dalam hal inovasi dan kemudahan karena nilai suatu produk atau jasa bagi pelanggan adalah produk yang lebih baik dan didukung oleh layanan yang memuaskan.

\section{Enhancing the profitability of existing customers}

Meningkatkan keuntungan yang diperoleh dari pelanggan yang sudah ada dengan mendorong terciptanya penjualan produk atau jasa komplemen dan penjualan produk atau jasa yang lebih baik dari produk atau jasa yang sudah dimiliki oleh pelanggan.

\section{Retaining profitable customers for life}

Fokus dari mempertahankan pelanggan yang memberi keuntungan adalah pada penyesuaian layanan-menawarkan apa yang dibutuhkan oleh pelanggan, bukan apa yang dibutuhkan oleh pasar karena nilai produk atau jasa bagi pelanggan adalah nilai hubungan produktif yang paling sesuai dengan kebutuhannya. Fokus perusahaan saat ini adalah bagaimana mempertahankan pelanggan yang menguntungkan bagi perusahaan daripada bagaimana mendapatkan pelanggan baru yang belum tentu memberi keuntungan.

Ketiga tahap itu saling berhubungan tetapi untuk dapat melakukan ketiga tahap tersebut dengan baik sangatlah sulit bahkan oleh perusahaan yang paling baik sekalipun. Untuk itu, perusahaan harus memilih untuk memfokuskan usahanya pada salah satu tahap tersebut. Hal itu sangat penting karena mempengaruhi strategi pembangunan infrastruktur, teknologi pendukung CRM ini. 




Gambar 2 Three Phase of CRM

Sumber: Kalakota (2000:114)

\section{Kemampuan Utama yang Dilakukan Customer Relationship Management}

Berdasarkan pendapat Kalakota (2000:118), kemampuan utama yang dapat dilakukan oleh Customer Relationship Management.

1. Cross-selling and Up-selling

Perusahaan harus dapat menciptakan hubungan yang lebih erat dengan pelanggan, yaitu dengan berusaha memenuhi kebutuhan pelanggan dengan produk/jasa komplemen.

\section{Direct Marketing and Fulfillment}

Pemasaran langsung dan pemenuhan permintaan berarti menjual dengan baik dan mengirimkan pesanan pelanggan secara cepat. Manajemen kampanye pemasaran (campaign management) mengatasi kesulitan dalam hal pemasaran dalam banyak saluran dengan memungkinkan perusahaan mengatur, mengintegrasikan, dan meningkatkan program pemasaran. Pemenuhan permintaan pelanggan yang efektif adalah dengan menyediakan informasi yang banyak sekali kepada pelanggan dan calon pelanggan secara cepat, mudah, dan efisien. 


\section{Customer Service and Support}

Aplikasi mendukung bagi petugas layanan pelanggan bekerja sama sehingga dapat mengatur dan meyelesaikan permintaan layanan dari pelanggan dan mendapatkan informasi detil yang dibutuhkan mengenai pelanggan. Tujuan yang hendak dicapai adalah agar dapat menyelesaikan permasalahan pelanggan dengan efektif dan efisien.

\section{Field Service Operations}

Operasi layanan di lapangan adalah perpanjangan layanan pelanggan yang dilakukan jika permasalahan tidak dapat diselesaikan lewat telepon dan membutuhkan pengiriman personil/barang secara fisik kepada pelanggan. Aplikasi pendukung memiliki kemampuan untuk mengatur jadwal pengiriman, mengatur logistik, dan persediaan, serta menangani kontrak dan pembukuan.

\section{Retention Management}

Menggunakan sumber daya perusahaan yang terbatas untuk pelanggan yang menguntungkan dengan cara membedakan pelanggan/segmentasi pelanggan berdasarkan tipe layanan yang didaftarkan dan juga historis transaksi. Untuk mencapai hasil yang efektif dibutuhkan pengambilan informasi pelanggan yang sangat detil sehingga perusahaan dapat melayani pelanggan dengan lebih personal dan membedakan antara pelanggan yang satu dengan pelanggan yang lain. Pelanggan yang tidak menguntungkan dipisahkan atau malah dibuang supaya tidak menghabiskan sumber daya perusahaan.

\section{Pedoman Membuat Customer Relationship Management}

Berdasarkan pendapat Rangkuti (2002:141-142), ada 8 pedoman dalam membuat Customer Relationship Management (CRM).

\section{Perencanaan}

Diperlukan perencanaan yang komprehensif pada saat menggabungkan ketrampilan dan sumber daya dari dua perusahaan yang independen sehingga dapat mencapai tujuan yang strategis.

\section{Trust and Self Interest}

Hubungan yang berhasil memerlukan kepercayaan dan penghargaan antara dua partner dan keduanya berniat untuk saling mempercayai dan saling menghargai kepentingan masingmasing.

\section{Konflik}

Konflik sering terjadi dan merupakan aspek penting dalam relationship. Partner harus cepat melakukan respon apabila terjadi konflik dan bertindak secara proaktif untuk mengatasi konflik ini. 
4. Struktur Kepemimpinan

Struktur leadership yang efektif dapat memperlancar koordinasi dan sistem pengambilan keputusan.

\section{Fleksibilitas}

Mengetahui interdependensi masing-masing partner merupakan faktor penting dalam membangun relationship yang berhasil. Partnership yang bersifat fleksibel dapat mengantisipasi perubahan.

\section{Perbedaan Budaya}

Perbedaan budaya berkaitan dengan tahap perkembangan industri, sistem politik, kepercayaan, ekonomi, dan sebagainya.

\section{Transfer Teknologi}

Kedua partner harus dapat mengembangkan teknologi dan transfer teknologi ke dalam bentuk aplikasi yang komersial.

\section{Pembelajaran dari Kekuatan yang Dimiliki oleh Partner}

\section{Cara Mengelola Customer Relationship}

Menurut Rangkuti (2002:152-153), tujuan mengelola Customer Relationship adalah menciptakan keunggulan kompetitif secara terus-menerus terhadap merek, produk, atau bahkan perusahaan yang dimiliki secara relatif dibandingkan dengan merek, produk, atau perusahaan pesaing. Agar perusahaan dapat memperoleh keunggulan kompetitif secara terus menerus, pengelolaan pelanggan secara profesional sangat diperlukan. Caranya sebagai berikut.

1. Lakukan survei mengenai kepuasan pelanggan secara benar dengan tujuan mengetahui hal berikut.

a. Faktor yang mempengaruhi tingkat kepuasan dan ketidakpuasan pelanggan.

b. Perilaku pelanggan (Customer Behaviour).

c. Kebutuhan dasar, keinginan, dan harapan pelanggan.

d. Pelanggan yang paling bernilai dalam segmen tertentu.

2. Tentukan segmen pelanggan yang menyumbangkan penghasilan terbesar bagi perusahaan (termasuk di dalamnya pelanggan potensial yang memiliki prospek berkembang cukup besar).

3. Tentukan variable dominan dari Customer Relationship. Variabel dominan ini adalah variabel yang paling penting dari menentukan sehingga pelanggan merasa puas sesuai dengan apa yang dibutuhkan pelanggan.

4. Kelola dan tingkatkan secara terus-menerus variabel dominan tersebut sehingga tetap berada di atas rata-rata yang diberikan pesaing. Caranya adalah dengan mengembangkan strategi pemasaran dan mengintegrasikan semua fungsi pemasaran yang bersifat strategis ke dalam database strategi pemasaran, sehingga dapat meningkatkan Customer Relationship secara kompetitif dan berkelanjutan. 


\section{Rumah Sakit}

\section{Definisi Rumah sakit}

SK Menteri Kesehatan RI No. 983/Menkes/SK/XI/1992 menyebutkan bahwa Rumah Sakit Umum adalah Rumah Sakit yang memberikan pelayanan kesehatan yang bersifat dasar, spesialistik, dan subspesialistik. Rumah Sakit mempunyai misi memberikan pelayanan kesehatan yang bermutu dan terjangkau oleh masyarakat dalam rangka meningkatkan derajat kesehatan masyarakat. Tugasnya adalah melaksanakan upaya kesehatan secara berdayaguna dan berhasil guna dengan mengutamakan upaya peningkatan dan pencegahan serta melaksanakan upaya rujukan.

Menurut pendapat Aditama (2000:5), Rumah Sakit adalah tempat yang harus dibangun, dilengkapi, dan dipelihara dengan baik untuk menjamin kesehatan dan keselamatan pasiennya dan harus menyediakan fasilitas yang lapang, tidak berdesakan, dan terjamin sanitasinya bagi kesembuhan pasien.

\section{Perbedaan Rumah Sakit dengan Industri Lainnya}

Menurut Aditama (2000:144), tiga ciri khas Rumah Sakit yang membedakannya dengan industri lain.

1. Kenyataan bahwa "bahan baku” dari industri jasa kesehatan adalah manusia.

Tujuan utamanya adalah melayani kebutuhan manusia, bukan semata-mata menghasilkan produk dengan proses dan biaya seefisien mungkin. Unsur manusia perlu mendapat tanggung jawab utama pengelola Rumah Sakit, khususnya menyakut pertimbangan etika dan nilai kehidupan manusia.

2. Kenyataan bahwa Industri Rumah Sakit yang disebut sebagai pelanggan (customer) tidak selalu mereka yang menerima pelayanan. Pasien adalah mereka yang diobati di Rumah Sakit. Akan tetapi, kadang-kadang bukan mereka sendiri yang menentukan di Rumah Sakit mana mereka dirawat. Mereka dirawat di Rumah Sakit mana dapat ditentukan pasien, dokter, pihak asuransi, maupun perusahaan. Bila ada upaya pemasaran jenis fasilitas kesehatan yang tersedia di rumah sakit, objek pemasarannya adalah dokter, bukan pasien.

3. Kenyataan menunjukkan pentingnya peran para profesional, seperti dokter, perawat, ahli farmasi, dan fisioterapi. Proporsi antara tenaga profesional dengan pekerja biasa di Rumah Sakit, lebih banyak dibandingkan dengan organisasi lainnya.

\section{Metode Penelitian}

Metode penelitian yang digunakan dalam penelitian ini adalah metode penelitian deskriptif dengan jenis penelitian studi kasus. Untuk proses pengumpulan data, peneliti menggunakan metode penelitian lapangan (field research) dan metode penelitian kepustakaan. Untuk menganalisis data digunakan analisis SWOT serta analisis Kuadran (Kartesius) untuk mengetahui seberapa besar pengaruh sistem CRM (dalam hal ini terbagi menjadi tiga fungsi utama, yaitu Acquisition, Enhance, and Retain) terhadap kepuasan pasien. 


\section{Jenis dan Metode Penelitian}

Jenis penelitian yang dilakukan pada penelitian ini adalah studi kasus. Peneliti melakukan analisis pada PJN Harapan Kita terhadap permasalahan atau kasus yang timbul dan dicari solusi pemecahan masalah yang terbaik. Metode yang digunakan dalam melakukan penelitian ini adalah metode deskriptif. Metode deskriptif adalah suatu metode yang digunakan dalam meneliti status sekelompok manusia, suatu obyek, suatu set kondisi, suatu sistem pemikiran, ataupun suatu kelas peristiwa pada masa sekarang. Tujuan penelitian deskriptif adalah untu membuat gambaran atau lukisan secara sistematis, faktual. dan akurat mengenai fakta, sifat, serta hubungan antarfenomena yang diselidiki.

\section{Definisi Operasional dan Instrumen Pengukuran}

A. Definisi Operasional

Variabel yang diteliti dalam penelitian ini terdiri dari tiga bagian yang mewakili fungsi atau tahap yang terdapat dalam Customer Relationship Management yaitu Acguire, Enhance, and Retain. Variabel tersebut sebagai berikut.

1. Kualitas Dokter dan Perawat PJN Harapan Kita.

2. Teknologi pengobatan/medis pada PJN Harapan Kita.

3. Kenyamanan, kebersihan dan kerapian ruangan PJN Harapan Kita.

4. Kualitas peralatan medis PJN Harapan Kita.

5. Kualitas dan ketersediaan obat-obatan PJN Harapan Kita.

6. Kualitas makanan dan minuman (higienis dan gizi).

7. Pelayanan pemeriksaan, pengobatan dan perawatan yang cepat dan tepat.

8. Perhatian intensif kepada pasien oleh Dokter.

9. Perhatian intensif kepada pasien oleh Perawat.

10. Program Rehabilitasi, Seminar dan Penyuluhan yang diselenggarakan PJN Harapan Kita.

11. Kecepatan pelayanan administrasi yang didukung oleh Data Base.

12. Paket pengobatan/perawatan yang disediakan oleh PJN Harapan Kita.

13. Asuransi Kesehatan bagi pasien PJN Harapan Kita.

14. Keberadaan JPS bagi pasien PJN Harapan Kita.

15. Perhatian dan respon terhadap keluhan pasien beserta keluarganya oleh Customer Service.

16. Pelayanan melalui Call Center yang disediakan oleh PJN Harapan Kita.

17. Penyampaian informasi kepada pasien melalui koresponden (surat dan brosur) yang dilakukan oleh PJN Harapan Kita.

18. Keberadaan fasilitas penyampaian dan pelayanan informasi melalui Website dan e-Mail yang disediakan oleh PJN Harapan Kita.

B. Instrumen Pengukuran

Dalam penelitian ini peneliti menggunakan kuesioner sebagai instrumen pengumpulan data dari para responden. Kuesioner diukur melalui skala Likert dalam bentuk checklist. Untuk pengukuran tingkat harapan pasien PJN Harapan Kita, jawaban atas kuesioner yang telah diisi responden diberi skor sebagai berikut:

1. Sangat penting 5

2. Penting 4 
3. Biasa-biasa

4. Tidak penting

5. Sangat tidak penting
3

2

1

Untuk mengukur tingkat pengalaman pasien PJN Harapan Kita, jawaban atas kuesioner yang telah diisi oleh responden diberi skor sebagai berikut.

1. Sangat puas

2. Puas

3. Biasa-biasa

4. Tidak puas

5. Sangat tidak puas
5

4

3

2

\section{Formula yang Digunakan}

Metode Kuadran (Kartesius) dengan rumus sebagai berikut.

$$
\begin{gathered}
\bar{x}=\frac{\sum x i}{n} \\
\overline{\bar{X}}=\frac{\sum_{i=1}^{n} \bar{x} i}{k}
\end{gathered}
$$$$
\bar{Y}=\frac{\sum Y i}{n}
$$$$
\overline{\bar{Y}}=\frac{\sum_{i=1}^{n} \bar{Y} i}{K}
$$

$$
\begin{array}{ll}
\bar{Y}=\text { skor rata-rata tingkat harapan pasien PJN Harapan Kita } \\
\bar{X}=\text { skor rata-rata tingkat pengalaman pasien PJN Harapan Kita } \\
\overline{\bar{Y}}=\text { rata-rata dari skor rata-rata tingkat harapan pasien PJN Harapan } \\
\quad \text { Kita } \\
\overline{\bar{X}}=\text { rata-rata dari skor rata-rata tingkat pengalaman pasien PJN } \\
\quad \text { Harapan Kita } \\
K=\begin{array}{l}
\text { banyaknya atribut/fakta yang dapat mempengaruhi kepuasan } \\
n=
\end{array} \\
\text { pasien PJN Harapan Kita }
\end{array}
$$

\section{Gambaran Umum Perusahaan}

1. Sejarah Pusat Jantung Nasional Harapan Kita

Berdirinya Pusat Jantung Nasional Harapan Kita bermula dari ide Perhimpunan Kardiologi Indonesia (PERKI) pada tahun 1960 tentang perlu adanya staf bagian Kardiologi. Ide 
ini lebih menguat dengan adanya staf bagian Kardiologi FKUI yang dididik di luar negeri serta didukung oleh Yayasan Jantung Indonesia (1981) yang dimotori oleh Almarhum Dr. Sukaman dan Almarhumah Ibu Hj. Hartinah Soeharto.

Pada tahun 1983 pembangunan gedung mulai dilaksanakan dan arsitektur gedung dibuat mirip dengan pusat jantung terbesar di Amerika, Houston Cardiac Center, dan dua tahun kemudian diresmikan pada tanggal 9 November 1985 dan Almarhum Dr. Sukaman ditetapkan sebagi Direktur pertama dengan surat Keputusan Pengurus Yayasan Harapan Kita No. 02/1985 tanggal 27 Maret 1985.

Pada awal diresmikan, PJN Harapan Kita yang terletak di jalan Letjen S. Parman Kav. 87 Slipi, Jakarta Barat langsung diserahkan kepemilikannya pada Pemerintah, dalam hal ini Departemen Kesehatan Republik Indonesia, sesuai dengan Surat Keputusan Pengurus Yayasan Harapan Kita No. 02/1985 tanggal 25 Maret 1985. Namun, karena PJN Harapan Kita merupakan rumah sakit khusus dengan teknologi tinggi yang memerlukan biaya operasi yang sangat besar, pengelolaannya diserahkan kepada Yayasan Harapan kita. dibentuklah Dewan Penyantun yang menetapkan Badan Pelaksanaan Harian Dewan Penyantun PJN Harapan Kita melalui Surat Keputusan No. 06/1985 tanggal 25 Oktober 1985.

Memasuki tahun 2002, PJN Harapan Kita berubah menjadi Perjan (Perusahaan Jawatan) dalam rangka mempertahankan prestasi yang telah dicapai yang menjadikan PJN Harapan Kita setaraf International dan mampu bersaing dengan Rumah Sakit yang ada di luar negeri khususnya di antara negara ASEAN. Diharapkan dengan menjadi Perjan, PJN Harapan Kita diberi kewenangan pengelolaan secara mandiri yang tidak didominasi oleh birokrasi dan hirarki yang berlebihan serta mampu menghidupi diri sendiri.

2. Visi

Visi PJN Harapan Kita adalah menjadi Rumah Sakit unggulan bidang kardiovaskuler yang berwawasan global dalam pelayanan pendidikan dan penelitian sehingga mampu menjadi Pusat Rujukan Kardiovaskuler yang optimal.

3. Misi

Misi PJN Harapan Kita adalah menyelenggarakan pelayanan paripurna yang prima dan terjangkau, pendidikan, dan penelitian yang bermutu secara mandiri, demi tercapainya kesehatan kardiovaskuler yang opimal dan merata.

4. Moto

Moto PJN Harapan Kita adalah “Kesehatan Anda Harapan Kita Semua”.

5. Tujuan

PJN Harapan Kita mempunyai tiga tujuan sebagai berikut.

a. Memberikan pelayanan kesehatan yang merata dan bermutu kepada masyarakat khususnya kepada pasien penyakit jantung dan pembuluh darah. 
b. Menyediakan pelayanan dan pengembangan sarana yang luas untuk pendidikan calon spesialis, subspesialis dan paramedis di bidang kesehatan jantung dan pembuluh darah.

c. Menyelenggarakan kegiatan penelitian dan pengembangan di bidang kesehatan jantung dan pembuluh darah serta penyebarluasan hasil penelitian.

Tujuan PJN Harapan Kita lima tahun mendatang (1999 - 2003)

"Membentuk kekuatan yang mampu tumbuh secara bertahap, berkesinambungan atas kemampuan sendiri, berpeluang ekonomi sehingga budaya asing kuat dalam lingkup pelayanan kardiovaskuler nasional maupun regional.”

6. Fungsi

Fungsi PJN Harapan Kita.

a. Melaksanakan upaya peningkatan kesehatan.

b. Melaksanakan upaya pencegahan terjadinya penyakit jantung dan pembuluh darah.

c. Melaksanakan upaya penyembuhan terhadap pasien penyakit jantung dan pembuluh darah.

d. Melaksanakan upaya rehabilitas terhadap pasien jantung dan pembuluh darah.

e. Melaksanakan asuhan dan pelayanan keperawatan.

f. Melaksanakan Rujukan.

g. Melaksanakan pendidikan dan pelatihan.

h. Melaksanakan penelitian-penelitian, pengembangan dan penyebarluasannya.

i. Melaksanakan administrasi umum dan keuangan.

\section{PEMBAHASAN}

\section{Analisis Penelitian}

\section{Analisis Kualitatif}

Dalam analisis Kualitatif, penulis menggunakan metode/analisis SWOT (Strengths, Weaknesses, Opportunities, and Threats). Proses penggunaan manajemen analisis SWOT menghendaki adanya suatu survei internal tentang strengths (kekuatan) dan weaknesses (kelemahan) serta survei eksternal atas opportunities (ancaman) dan threats (peluang/kesempatan). Analisis SWOT secara sederhana dipahami sebagai pengujian terhadap kekuatan dan kelemahan internal sebuah organisasi, serta kesempatan dan ancaman lingkungan eksternalnya. Berikut adalah hasil analisis SWOT yang penulis lakukan terhadap lingkungan internal dan lingkungan eksternal pada Pusat Jantung Nasional Harapan Kita. 


\begin{tabular}{|c|c|}
\hline \begin{tabular}{ll||} 
& \multicolumn{1}{c||}{ Potensi } \\
1. & Dekuatan Internal (S) \\
2. & Teknologi medis yang mutakhir \\
3. & Kualitas dan ketersediaan obat-obatan \\
4. & Kecepatan pelayanan administrasi yang \\
& didukung Sistem Komputer \\
5. & Pelayanan Telekardiografi Nasional \\
& yang memungkinkan diagnosis \\
& jantung jarak jauh
\end{tabular} & \begin{tabular}{ll} 
& \multicolumn{1}{c}{ Potensi } \\
1. & Kenyamananan, kebersihan dan \\
& kerapian yang dirasa kurang \\
2. & Sistem penyampaian informasi \\
& kepada pasien yang kurang berjalan
\end{tabular} \\
\hline  & \begin{tabular}{ll} 
& \multicolumn{1}{c}{ Potensi } \\
1. & Persaingan dari Rumal Sakit sejenis \\
lainnya \\
2. Pemasok peralatan medis non mesin \\
dan obat-obatan diluar PJN Harapan \\
Kita
\end{tabular} \\
\hline
\end{tabular}

Gambar 3 Analisis SWOT

\section{Analisis Kuantitatif}

Dalam analisis ini, penulis diminta oleh pihak PJN Harapan Kita untuk memberikan juga laporan tiap kelas ruang perawatan sebagai masukan kepada pihak rumah sakit. Untuk itu penulis berusaha memasukkan analisis untuk tiap kelas ruang perawatan sesuai dengan permintaan pihak rumah sakit walaupun bukan dalam bentuk analisis Kuadran (Kartesius). Penulis berusaha meneliti berdasarkan tingkat kesesuaian antara harapan pasien pada tiap kelas ruang perawatan dan pelaksanaannya di masing-masing kelas. Oleh karena itu, pada subbab ini dibagi dua bagian oleh penulis, yaitu analisis menurut kelas ruang perawatan dan analisis secara keseluruhan. 


\section{Analisis Menurut Kelas Ruang Perawatan}

Tabel 1 Jumlah Sampel Per Kelas Ruang Perawatan

\begin{tabular}{lccccccc}
\hline Sampel & SVIP & VIP & Kelas 1 & Kelas 2 & Kelas 3 & ICU/CVCU & Total \\
\hline \hline Pasien & 2 & 6 & 7 & 10 & 10 & - & 35 \\
\hline Keluarga Pasien & 3 & 11 & 11 & 6 & 9 & 25 & 65 \\
\hline Total & 5 & 17 & 18 & 16 & 19 & 25 & 100 \\
\hline
\end{tabular}

Sumber: Hasil Penghitungan Kuesioner

Tabel 2 Tingkat Kesesuaian Pengalaman dan Harapan Pasien PJN Harapan Kita

\begin{tabular}{|c|c|c|c|c|c|c|c|c|}
\hline No. & $\begin{array}{c}\text { Faktor-faktor yang } \\
\text { mempengaruhi Kepuasan Pasien } \\
\text { PJN Harapan Kita }\end{array}$ & $\begin{array}{l}\text { SVIP } \\
(\%)\end{array}$ & $\begin{array}{l}\text { VIP } \\
(\%)\end{array}$ & $\begin{array}{c}\text { Kelas } \\
1 \\
(\%)\end{array}$ & $\begin{array}{c}\text { Kelas } \\
2 \\
(\%)\end{array}$ & $\begin{array}{c}\text { Kelas } \\
3 \\
(\%)\end{array}$ & $\begin{array}{c}\text { ICU/CVCU } \\
(\%)\end{array}$ & $\begin{array}{c}\text { Rata- } \\
\text { rata } \\
(\%)\end{array}$ \\
\hline \multicolumn{9}{|c|}{ A. Acguire } \\
\hline 1 & Kualitas Dokter dan Perawat & 88.00 & 87.34 & 83.72 & 87.01 & 82.80 & 88.79 & 86.28 \\
\hline 2 & Teknologi pengobatan/medis & 91.67 & 91.25 & 87.21 & 88.00 & 85.87 & 89.66 & 88.94 \\
\hline 3 & $\begin{array}{l}\text { Kenyamanan, kebersihan dan } \\
\text { kerapian }\end{array}$ & 100.00 & 78.08 & 84.81 & 78.38 & 73.03 & 76.32 & 81.77 \\
\hline 4 & Kualitas peralatan medis & 87.50 & 94.59 & 87.95 & 88.89 & 83.02 & 89.19 & 88.52 \\
\hline 5 & $\begin{array}{l}\text { Kualitas dan ketersediaan obat- } \\
\text { obatan }\end{array}$ & 95.65 & 93.06 & 91.36 & 84.51 & 90.80 & 87.61 & 90.50 \\
\hline 6 & Kualitas makanan dan minuman & 90.48 & 95.45 & 88.31 & 86.96 & 87.06 & 87.96 & 89.37 \\
\hline \multicolumn{9}{|c|}{ B. Enhance } \\
\hline 7 & $\begin{array}{l}\text { Pelayanan pemeriksaan, } \\
\text { pengobatan dan perawatan }\end{array}$ & 90.19 & 94.44 & 82.50 & 90.00 & 83.33 & 79.46 & 86.65 \\
\hline 8 & Perhatian intensif oleh Dokter & 91.67 & 90.67 & 81.18 & 84.00 & 89.77 & 87.27 & 87.43 \\
\hline 9 & Perhatian intensif oleh Perawat & 95.45 & 84.29 & 88.10 & 88.89 & 88.76 & 86.79 & 88.71 \\
\hline 10 & $\begin{array}{l}\text { Program Rehabilitasi, Seminar dan } \\
\text { Penyuluhan }\end{array}$ & 80.00 & 87.69 & 89.47 & 89.71 & 90.67 & 89.22 & 87.79 \\
\hline 11 & $\begin{array}{l}\text { Pelayanan administrasi oleh } \\
\text { Sistem Komputer }\end{array}$ & 91.30 & 95.83 & 85.54 & 83.33 & 84.88 & 87.62 & 88.08 \\
\hline 12 & Paket pengobatan/perawatan & 95.00 & 96.92 & 87.50 & 92.45 & 86.05 & 86.67 & 90.77 \\
\hline 13 & Asuransi Kesehatan & 84.21 & 82.09 & 79.52 & 84.29 & 86.75 & 85.71 & 83.76 \\
\hline 14 & Keberadaan JPS dan Gakin & 84.21 & 77.61 & 76.62 & 85.07 & 76.19 & 81.82 & 80.25 \\
\hline \multicolumn{9}{|c|}{ C. Retain } \\
\hline 15 & Customer Service & 95.24 & 93.94 & 83.75 & 76.71 & 80.25 & 87.74 & 86.27 \\
\hline 16 & Call Center & 100.00 & 96.92 & 82.28 & 79.41 & 87.84 & 89.90 & 89.39 \\
\hline 17 & Koresponden (surat dan brosur) & 90.00 & 93.55 & 79.22 & 81.25 & 84.51 & 82.00 & 85.09 \\
\hline 18 & Website dan e-Mail & 94.12 & 94.74 & 77.33 & 79.10 & 86.49 & 84.85 & 86.12 \\
\hline
\end{tabular}




\section{Analisis Secara Keseluruhan}

Di dalam analisis secara keseluruhan ini, penulis menggunakan analisis Kuadran (Kartesius) yang menjelaskan mengenai tingkat harapan pasien dan tingkat pengalaman pasien.

\section{Analisis Kuadran (Kartesius)}

Dari seratus responden yang diteliti, diperoleh tingkat harapan pasien dan tingkat pengalaman pasien seperti yang tertera pada Tabel berikut ini.

Tabel 3 Penghitungan Rata-rata dari Penilaian Pengalaman dan Harapan pada Faktor yang Mempengaruhi Kepuasan Pasien PJN Harapan Kita

\begin{tabular}{|c|c|c|c|c|c|c|}
\hline No. & $\begin{array}{c}\text { Faktor yang mempengaruhi } \\
\text { Kepuasan Pasien PJN } \\
\text { Harapan Kita } \\
\end{array}$ & Pengalaman & Harapan & $X$ & $\boldsymbol{Y}$ & Tingkat Kesesuaian \\
\hline \multicolumn{7}{|c|}{ A. Acguire } \\
\hline 1 & Kualitas Dokter dan Perawat & 410 & 476 & 4.10 & 4.76 & $86.13 \%$ \\
\hline 2 & Teknologi pengobatan/medis & 419 & 473 & 4.19 & 4.73 & $88.58 \%$ \\
\hline 3 & $\begin{array}{l}\text { Kenyamanan, kebersihan dan } \\
\text { kerapian }\end{array}$ & 356 & 451 & 3.56 & 4.51 & $78.94 \%$ \\
\hline 4 & Kualitas peralatan medis & 407 & 450 & 4.07 & 4.50 & $90.44 \%$ \\
\hline 5 & $\begin{array}{l}\text { Kualitas dan ketersediaan } \\
\text { obat-obatan }\end{array}$ & 401 & 447 & 4.01 & 4.47 & $89.71 \%$ \\
\hline 6 & $\begin{array}{l}\text { Kualitas makanan dan } \\
\text { minuman }\end{array}$ & 379 & 426 & 3.79 & 4.26 & $88.97 \%$ \\
\hline \multicolumn{7}{|c|}{ B. Enhance } \\
\hline 7 & $\begin{array}{l}\text { Pelayanan pemeriksaan, } \\
\text { pengobatan dan perawatan }\end{array}$ & 389 & 446 & 3.89 & 4.46 & $87.22 \%$ \\
\hline 8 & Perhatian intensif oleh Dokter & 397 & 457 & 3.97 & 4.57 & $86.87 \%$ \\
\hline 9 & $\begin{array}{l}\text { Perhatian intensif oleh } \\
\text { Perawat }\end{array}$ & 391 & 443 & 3.91 & 4.43 & $88.26 \%$ \\
\hline 10 & $\begin{array}{l}\text { Program Rehabilitasi, } \\
\text { Seminar dan Penyuluhan }\end{array}$ & 361 & 406 & 3.61 & 4.06 & $88.92 \%$ \\
\hline 11 & $\begin{array}{l}\text { Pelayanan administrasi oleh } \\
\text { Sistem Komputer }\end{array}$ & 386 & 441 & 3.86 & 4.41 & $87.53 \%$ \\
\hline 12 & Paket pengobatan/perawatan & 379 & 423 & 3.79 & 4.23 & $89.60 \%$ \\
\hline 13 & Asuransi Kesehatan & 358 & 427 & 3.58 & 4.27 & $83.84 \%$ \\
\hline 14 & Keberadaan JPS dan Gakin & 338 & 424 & 3.38 & 4.24 & $79.72 \%$ \\
\hline \multicolumn{7}{|c|}{ C. Retain } \\
\hline 15 & Customer Service & 363 & 427 & 3.63 & 4.27 & $85.01 \%$ \\
\hline 16 & Call Center & 357 & 405 & 3.57 & 4.05 & $88.15 \%$ \\
\hline 17 & $\begin{array}{l}\text { Koresponden (surat dan } \\
\text { brosur) }\end{array}$ & 331 & 394 & 3.31 & 3.94 & $84.01 \%$ \\
\hline 18 & Website dan e-Mail & 329 & 389 & 3.29 & 3.89 & $84.58 \%$ \\
\hline \multicolumn{4}{|c|}{ Rata-rata $(\overline{\bar{X}}$ dan $\overline{\bar{Y}})$} & 3.75 & 4.34 & \\
\hline
\end{tabular}

Sumber: Hasil Penghitungan Kuesioner 
Keterangan: $\bar{X}$ dan $\bar{Y}=$ nilai rata-rata dari 100 orang responden $\overline{\bar{X}}$ dan $\overline{\bar{Y}}=$ nilai rata-rata dari rata-rata $(\bar{X}$ dan $\bar{Y})$

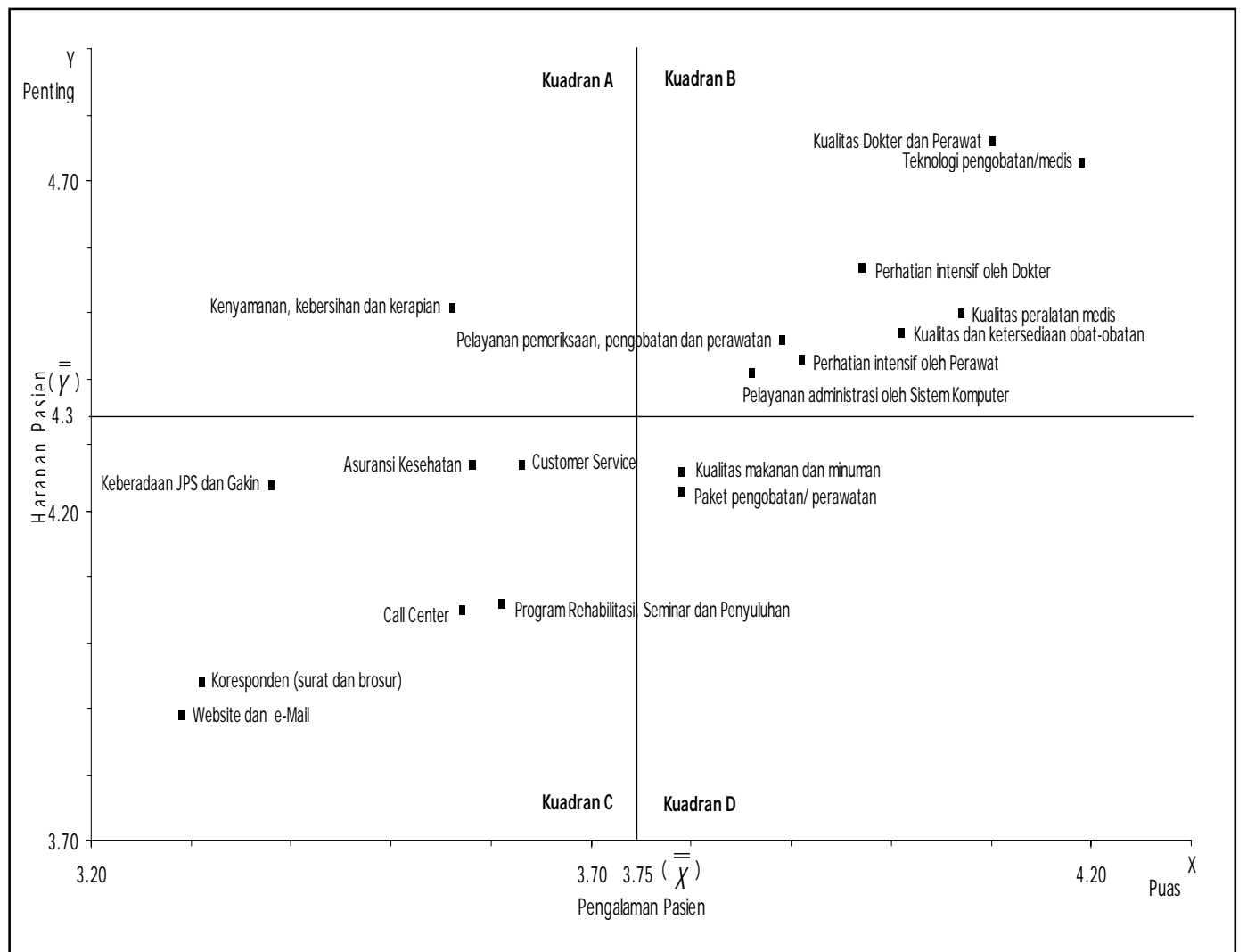

Sumber: Hasil output Microsoft Excel

Gambar 4 Diagram Kartesius Faktor yang Mempengaruhi

Kepuasan Pasien PJN Harapan Kita

Hasil pengukuran unsur jasa ini berdasarkan tingkat kepentingan dan kinerjanya yang memungkinkan pihak PJN Harapan Kita untuk dapat menitikberatkan usaha perbaikan untuk hal atau atribut yang benar-benar dianggap penting oleh para pasien PJN Harapan Kita agar dapat memuaskan. Untuk memperoleh titik-titik pada Diagram Kartesius (Gambar di atas), sebelumnya perlu dihitung terlebih dahulu nilai rata-rata dari rata-rata. Hasil hitungan terlihat pada Tabel di atas.

Dalam Diagram Kartesius ini terlihat bahwa letak unsur pelaksanaan faktor atau atribut yang mempengaruhi kepuasan pasien PJN Harapan Kita terbagi menjadi empat bagian. Interpretasi diagram Kartesius tersebut dapat dijelaskan sebagai berikut. 


\section{Kuadran A}

Menunjukkan faktor atau atribut yang mempengaruhi kepuasan pasien PJN Harapan Kita berada dalam Kuadran ini dan penanganannya perlu diprioritaskan karena keberadaan faktor inilah yang dinilai sangat penting oleh pasien sedangkan tingkat pelaksanaannya masih belum memuaskan.

Faktor yang termasuk Kuadran ini adalah kenyamanan, kebersihan, dan kerapian ruangan PJN Harapan Kita (No. 3)

\section{Kuadran B}

Menunjukkan faktor atau atribut yang mempengaruhi kepuasan pasien PJN Harapan Kita. Kuadran ini perlu dipertahankan karena pada umumnya tingkat pelaksanaannya telah sesuai dengan kepentingan dan harapan pasien, sehingga dapat memuaskan pasien PJN Harapan Kita. Faktor yang termasuk dalam Kuadran B ini sebagai berikut.

a. Teknologi pengobatan/medis pada PJN Harapan Kita (No. 2)

b. Kualitas Dokter dan Perawat PJN Harapan Kita (No. 1)

c. Kualitas peralatan medis PJN Harapan Kita (No. 4)

d. Kualitas dan ketersediaan obat-obatan PJN Harapan Kita (No. 5)

e. Perhatian intensif kepada pasien oleh Dokter (No. 8)

f. Perhatian intensif kepada pasien oleh Perawat (No. 9)

g. Pelayanan pemeriksaan, pengobatan dan perawatan yang cepat dan tepat (No. 7)

h. Kecepatan pelayanan administrasi yang didukung oleh Sistem Komputer (No. 11)

3. Kuadran C

Menunjukkan bahwa faktor yang mempengaruhi kepuasan pasien PJN Harapan Kita berada dalam kuadran ini dinilai masih dianggap kurang penting bagi pasien sedangkan kualitas pelaksanaannya biasa atau cukup saja. Faktor yang termasuk didalam Kuadran C.

a. Perhatian dan respon terhadap keluhan pasien beserta keluarganya oleh Customer Service (No. 15)

b. Program Rehabilitasi, Seminar, dan Penyuluhan yang diselenggarakan PJN Harapan Kita (No. 10)

c. Asuransi Kesehatan bagi pasien PJN Harapan Kita (No. 13)

d. Pelayanan melalui Call Center yang disediakan oleh PJN Harapan Kita (No. 16)

e. Keberadaan JPS (Jaring Pengaman Sosial) dan Gakin (Keluarga Miskin) bagi pasien tidak mampu (No. 14)

f. Penyampaian informasi kepada pasien melalui koresponden (surat dan brosur) yang dilakukan oleh PJN Harapan Kita (No. 17)

g. Keberadaan fasilitas penyampaian dan pelayanan informasi melalui Website dan e-Mail yang disediakan oleh PJN Harapan Kita (No. 18)

4. Kuadran D

Menunjukkan bahwa faktor yang mempengaruhi kepuasan pasien PJN Harapan Kita berada dalam kuadran ini dinilai berlebihan dalam pelaksanaannya. Hal itu terutama karena 
pelanggan menganggap tidak terlalu penting terhadap adanya faktor tersebut. Akan tetapi, pelaksanaannya dilakukan dengan baik oleh PJN Harapan Kita sehingga sangat memuaskan. Faktor yang termasuk didalam Kuadran D.

a. Kualitas makanan dan minuman (higienis dan gizi) (No. 6)

b. Paket pengobatan/perawatan yang disediakan oleh PJN Harapan Kita (No. 12)

\section{Evaluasi Customer Relationship Management}

Berikut adalah evaluasi yang dilakukan oleh penulis, diperoleh penghitungan rata-rata variabel yang ada pada tahap CRM (Acguire, Enhance and Retain) terhadap faktor yang mempengaruhi kepuasan pasien PJN Harapan Kita, seperti yang terlihat pada Tabel berikut ini.

Tabel 4 Penilaian Pengalaman dan Penilaian Harapan pada Faktor yang Mempengaruhi Kepuasan Pasien PJN Harapan Kita

\begin{tabular}{|c|c|c|c|c|c|}
\hline No. & $\begin{array}{c}\text { Faktor-faktor yang mempengaruhi Kepuasan } \\
\text { Pasien PJN Harapan Kita }\end{array}$ & $\bar{x}$ & $\bar{Y}$ & $\begin{array}{l}\overline{\boldsymbol{X}} \\
\operatorname{Var}\end{array}$ & $\begin{array}{l}\overline{\boldsymbol{Y}} \\
\text { Var }\end{array}$ \\
\hline \multicolumn{6}{|c|}{ A. Acguire } \\
\hline 1 & Kualitas Dokter dan Perawat & 4.10 & 4.76 & \multirow{6}{*}{3.95} & \multirow{6}{*}{4.54} \\
\hline 2 & Teknologi pengobatan/medis & 4.19 & 4.73 & & \\
\hline 3 & Kenyamanan, kebersihan dan kerapian & 3.56 & 4.51 & & \\
\hline 4 & Kualitas peralatan medis & 4.07 & 4.50 & & \\
\hline 5 & Kualitas dan ketersediaan obat-obatan & 4.01 & 4.47 & & \\
\hline 6 & Kualitas makanan dan minuman & 3.79 & 4.26 & & \\
\hline \multicolumn{6}{|c|}{ B. Enhance } \\
\hline 7 & $\begin{array}{l}\text { Pelayanan pemeriksaan, pengobatan dan perawatan } \\
\text { yang cepat }\end{array}$ & 3.89 & 4.46 & \multirow{8}{*}{3.75} & \multirow{8}{*}{4.33} \\
\hline 8 & Perhatian intensif oleh Dokter & 3.97 & 4.57 & & \\
\hline 9 & Perhatian intensif oleh Perawat & 3.91 & 4.43 & & \\
\hline 10 & Program Rehabilitasi, Seminar dan Penyuluhan & 3.61 & 4.06 & & \\
\hline 11 & Pelayanan administrasi oleh Sistem Komputer & 3.86 & 4.41 & & \\
\hline 12 & Paket pengobatan/perawatan & 3.79 & 4.23 & & \\
\hline 13 & Asuransi Kesehatan & 3.58 & 4.27 & & \\
\hline 14 & Keberadaan JPS dan Gakin & 3.38 & 4.24 & & \\
\hline \multicolumn{6}{|c|}{ C. Retain } \\
\hline 15 & Customer Service & 3.63 & 4.27 & \multirow{4}{*}{3.45} & \multirow{4}{*}{4.04} \\
\hline 16 & Call Center & 3.57 & 4.05 & & \\
\hline 17 & Koresponden (surat dan brosur) & 3.31 & 3.94 & & \\
\hline 18 & Website dan e-Mail & 3.29 & 3.89 & & \\
\hline
\end{tabular}




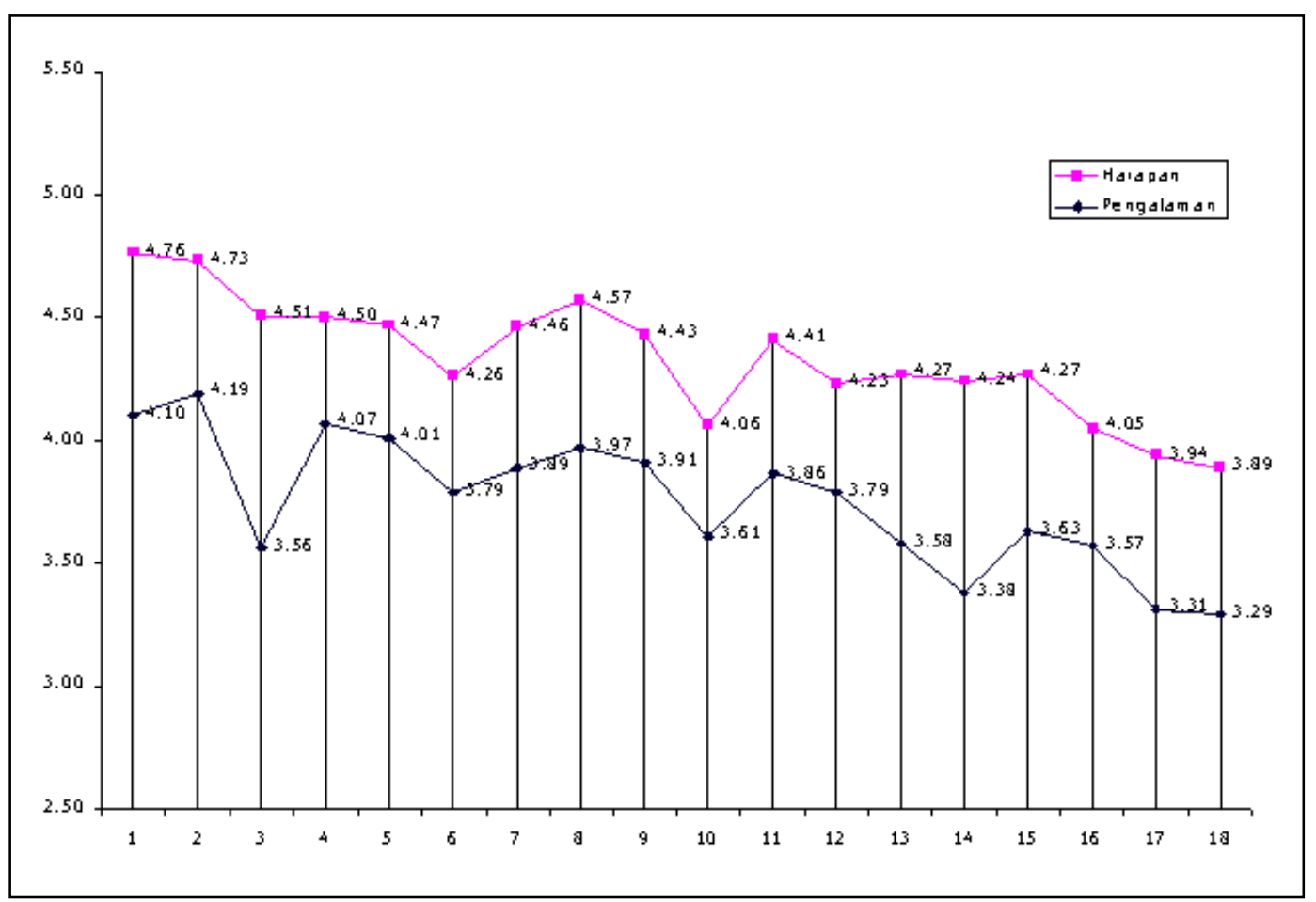

Faktor yang mempengaruhi kepuasan pasien

Gambar 5 Penilaian Harapan dan Pengalaman pasien Sumber: Hasil output Microsoft Excel

Tabel di atas menunjukkan bahwa pada tahap Acguire diperoleh rata-rata variance (Pengalaman dan Harapan Pasien) yang lebih besar dibandingkan pada tahap lainnya (Enhance dan Retain). hal itu karena tahap Acguire merupakan tahap yang dominan dalam menunjang kepuasan pasien dan kesembuhan merupakan kebutuhan fundamental dari pihak pasien. Akan tetapi, pelaksanaan pada tahap Acguire ini masih dinilai kurang dibandingkan dengan harapan pasien. Untuk itu tahap Acguire sebagai faktor dominan harus ditingkatkan agar sesuai dengan tingkat harapan pasien dan dapat menjadi keunggulan dalam bersaing dengan rumah sakit lainnya.

Tahap Enhance dan Retain menunjukkan juga nilai rata-rata variance pelaksanaan yang belum memenuhi harapan pasien. Oleh karena itu, kedua tahap itu sebaiknya ditingkatkan sehingga memenuhi harapan pasien. Kedua tahap CRM itu menunjang faktor dominan (Acguire) dalam memenuhi kepuasan pasien.

Ketiga tahap CRM (Acguire, Enhance, and Retain) saling berhubungan dan menunjang satu sama lain sehingga menjadi satu kesatuan. Akan tetapi, untuk dapat melakukan ketiga tahap tersebut dengan baik sangat sulit jika dilakukan secara bersamaan. Untuk itu, PJN Harapan Kita harus memprioritaskan pada tahap CRM yang sesuai dengan ruang lingkup bidang usahanya yang dimulai dari faktor yang paling dominan. Peningkatan terhadap CRM PJN Harapan Kita sebaiknya dimulai dari tahap yang paling dominan, yaitu tahap Acguire, kemudian tahap Enhance, dan 
terakhir Retain. Hal itu karena tahap tersebut diprioritaskan berdasarkan nilai rata-rata variance harapan dari yang terbesar ke yang terkecil.

Penulis berpendapat bahwa pada tahap Acguire, PJN Harapan Kita harus memusatkan perhatian pada faktor kenyamanan, kebersihan, dan kerapian ruangan. Hal itu karena dari analisis yang telah dilakukan penulis, menunjukkan kurangnya pelayanan pada faktor tersebut. Pada tahap Enhance, penulis berpendapat agar PJN Harapan Kita memusatkan perhatian pada program yang dapat meringankan biaya pasien. Hal itu sesuai dengan Misi PJN Harapan Kita, yaitu menyelenggarakan pelayanan paripurna yang prima dan terjangkau.

Di tahap Retain, penulis berpendapat agar PJN Harapan Kita memusatkan perhatian pada sarana penyampaian informasi kepada pasien karena berdasarkan bincang penulis dengan beberapa responden, mereka sangat mengharapkan perhatian dari PJN Harapan Kita walaupun mereka sedang tidak dirawat di PJN Harapan Kita. Hal itu sesuai dengan Misi PJN Harapan Kita, yaitu menyelenggarakan pelayanan paripurna yang prima.

\section{PENUTUP}

\section{Simpulan}

I. Berdasarkan hasil analisis Kuadran (Kartesius) terhadap faktor yang mempengaruhi kepuasan pasien PJN Harapan Kita, dapat diketahui hal berikut.

1. Faktor berikut adalah faktor yang dianggap penting oleh pasien dan PJN Harapan Kita telah melaksanakannya dengan baik (Kuadran B).

a. Teknologi pengobatan/medis pada PJN Harapan Kita.

b. Kualitas Dokter dan Perawat PJN Harapan Kita.

c. Kualitas peralatan medis PJN Harapan Kita.

d. Kualitas dan ketersediaan obat-obatan PJN Harapan Kita.

e. Perhatian intensif kepada pasien oleh Dokter.

f. Perhatian intensif kepada pasien oleh Perawat.

g. Pelayanan pemeriksaan, pengobatan dan perawatan yang cepat dan tepat.

h. Kecepatan pelayanan administrasi yang didukung oleh Sistem Komputer.

2. Faktor berikut adalah faktor yang dianggap tidak penting oleh pasien tetapi pelaksanaannya dilakukan dengan baik oleh PJN Harapan Kita (Kuadran D).

a. Kualitas makanan dan minuman (higienis dan gizi).

b. Paket pengobatan/perawatan yang disediakan oleh PJN Harapan Kita.

3. Faktor berikut adalah faktor yang dianggap penting oleh pasien namun PJN Harapan Kita belum melaksanakannya sebagaimana yang diharapkan pasien (Kuadran A), yaitu kenyamanan, kebersihan, dan kerapian ruangan PJN Harapan Kita. 
4. Faktor berikut adalah faktor yang dianggap tidak penting oleh pasien dan pihak PJN Harapan Kita juga kurang melaksanakannya dengan baik (Kuadran C).

a. Perhatian dan respons terhadap keluhan pasien beserta keluarganya oleh Customer Service.

b. Program Rehabilitasi, Seminar, dan Penyuluhan yang diselenggarakan PJN Harapan Kita.

c. Asuransi Kesehatan bagi pasien PJN Harapan Kita.

d. Pelayanan melalui Call Center yang disediakan oleh PJN Harapan Kita.

e. Keberadaan JPS (Jaring Pengaman Sosial) dan Gakin (Keluarga Miskin) bagi pasien tidak mampu.

f. Penyampaian informasi kepada pasien melalui koresponden (surat dan brosur) yang dilakukan oleh PJN Harapan Kita.

g. Keberadaan fasilitas penyampaian dan pelayanan informasi melalui Website dan $e$ Mail yang disediakan oleh PJN Harapan Kita

II. Berdasarkan hasil evaluasi CRM PJN Harapan Kita, dapat diketahui tahap peningkatan CRM di PJN Harapan Kita.

1. Peningkatan faktor yang berada di tahap yang paling dominan, yaitu tahap Acguire terutama pada faktor kenyamanan, kebersihan, dan kerapian ruangan.

2. Tahap selanjutnya adalah tahap Enhance, terutama program untuk meringankan biaya yang harus ditanggung pasien.

3. Terakhir adalah Retain, khususnya peningkatan sarana penyampaian informasi kepada pasien.

III. Faktor yang perlu mendapat perhatian utama (Kuadran A), yaitu faktor kenyamanan, kebersihan, dan kerapian ruangan PJN Harapan Kita merupakan faktor yang dianggap penting oleh pasien namun PJN Harapan Kita belum melaksanakannya sebagaimana yang diharapkan pasien. Oleh karena itu, sebaiknya pihak PJN Harapan Kita lebih memusatkan perhatian pada faktor ini. Apabila PJN Harapan Kita ingin meningkatkan faktor ini, mungkin dapat dilakukan dengan penambahan tenaga kerja cleanning service seiring dengan jumlah pasien yang dirawat di setiap kelas/ruang perawatan. Selain itu, sebaiknya dilakukan juga peningkatan sistem pengawasan dan pengendalian pada unit kerja cleaning service.

IV. Faktor yang dianggap tidak penting oleh pasien dan pihak PJN Harapan Kita juga kurang melaksanakannya dengan baik (Kuadran C). Sebaiknya pada masa mendatang perlu dilaksanakan yang sewajarnya saja karena walaupun faktor tersebut dianggap tidak penting oleh pasien tetapi faktor tersebut memberikan kontribusi dalam pembentukan CRM yang baik di PJN Harapan Kita.

V. Faktor yang dianggap tidak penting oleh pasien tetapi pelaksanaannya dilakukan dengan baik oleh PJN Harapan Kita (Kuadran D). Sebaiknya pada masa mendatang penanganannya dilakukan seefisien mungkin.

VI. Faktor yang dianggap penting oleh pasien dan PJN Harapan Kita telah melaksanakannya dengan baik (Kuadran B), sebaiknya terus dipertahankan bahkan perlu ditingkatkan agar mampu memberikan kepuasan yang lebih kepada pasien. 
VII. Agar dapat memperoleh keunggulan kompetitif secara terus-menerus, disarankan sebaiknya dilakukan juga penelitian terhadap faktor yang mempengaruhi kepuasan pasien diluar CRM PJN Harapan Kita seperti perilaku pasien, daya beli pasien, dan lain-lain.

VIII. Mengingat penelitian yang dilakukan oleh penulis hanya pada sebagian kelas rawat inap, disarankan agar dilakukan penelitian yang menyeluruh di PJN Harapan Kita. Selain itu, hendaknya dilakukan juga peningkatan pelayanan PJN Harapan Kita secara terus-menerus mengingat kebutuhan pasien yang selalu meningkat.

\section{DAFTAR PUSTAKA}

Aditama, Tjandra Yoga. 2000. Management Rumah Sakit. Jakarta: Universitas Indonesia.

Brown, Stanley. 2000. Customer Relationship Management: A Strategic Imperative in the World of E-Business. [WWW Document. URL http://www.amazon.com].

Ciptamaya. 1997. Definisi CRM. [WWW Document. URL http://www.indocrm.com/Others /indeks.cfm?fuseaction=tentang_crm].

Dyche, Jill. 2001. The CRM Handbook: A Business Guide To CRM. [WWW Document. URL http://www.amazon.com].

Irawan, Handi. 2002. 10 Prinsip Kepuasan Pelanggan. Jakarta: PT Elex Media Komputindo.

Kalakota, Ravi. 2000. e-Business: Roadmap for Success. Massachusetts: Addison Wesley Longman, Inc.

Kotler, Philip. 1997. Manajemen Pemasaran: Analisis, Perencanaan, Implementasi dan Kontrol. Jilid 1. Jakarta: PT Prenhallindo.

Rangkuti, Freddy. 2002. Measuring Customer Satisfaction. Jakarta: PT Gramedia Pustaka Utama.

Tjiptono, Fandy. 1997. Prinsip-prinsip Total Quality Service. Yogyakarta: Andi Offset.

Yoeti, H. Oka A. 1999. Customer Service Cara Efektif Memuaskan Pelanggan. Jakarta: Pradnya Paramita. 